\title{
Morphometrical Nuclear Investigation Of The Central Region In Basaloid Cell Cutaneous Neoplasms
}

\author{
O.D. Ribeiro,* M.A. Guzmán-Silva,* and M.C. Rochael* \\ * Department of Pathology, Universidade Federal Fluminense, Niteroi, RJ, Brazil, 24030-210
}

The basal cell carcinoma (BCC) is the most frequent neoplasia in populations of white genetic background and in spite of the infrequent metastasis, destructive and invasive behavior cannot be despised [1]. Other benign neoplasms also present morphologic characteristics similar to the $\mathrm{BCC}$, among them neoplasms of follicular origin as the trichoblastoma (TB) and the trichoepithelioma (TE). Both are part of the differential diagnoses for this tumor [1].

To evaluate the possibilities to differentiate these neoplasms, we performed an morphometrical study of 50 lesions. Thirty were BCC - 10 of each subtype, sclerodermiform (Scl), nodular (Nod), and superficial (Sup) - 10 trichoblastomas, and 10 trichoepitheliomas. From each one of the 50 selected lesions, 10 images of central fields of the tumor nest were digitalized. Digitalization was performed through a JVC camera, TK 1270 model, coupled to a ZEISS optical microscope, under x400 amplification. The nuclear parameters were analyzed by a macro created for this purpose (Fig. 1, Table 1 \& 2) in the Kontron Elektronic KS300 system. The nuclear area, perimeter, minimum diameter (MIND), maximum diameter (MAXD), elliptic factor (EF), and regularity factor (RF) were obtained. The mean value and the standard deviation (Table 3) of each parameter were calculated. The results were submitted to the Mann-Whitney U non-parametric test using the program SPSS 9.0 and the values with $\mathrm{P} \leq 0.05$ were considered significant. With the statistical analysis of the mean values we verified the existence of significant difference in 30 comparisons. Nuclear perimeter and maximum diameter were the parameters that most frequently showed statistical differences among the investigated neoplasms. Those values for the sclerodermiform and the nodular BCC were higher than the superficial one, the trichoblastoma and the trichoepithelioma. In the same way, the values of the standard deviation of each of the morphometrical parameter were analyzed comparing the central region of basaloid cell cutaneous neoplasms, once those values would serve as indicative of the nuclear pleomorphism [2]. With this approach we found significant difference in 26 comparisons, being the maximum diameter and the elliptic factor the most frequent parameters with differences. Both parameters, together with nuclear area, perimeter, and minimum diameter, allow to distinguish the sclerodermiform BCC from the superficial one, the trichoblastoma and the trichoepithelioma.

We conclude that comparative morphometrical nuclear investigation in the central region between basaloid cell cutaneous neoplasms allows to specially distinguish the sclerodermiform BCC from the superficial one, the trichoblastoma and the trichoepithelioma. The higher nuclei pleomorfism of the central region in sclerodermiform BCC could be related to the aggressive biological behavior of this basaloid cell cutaneous neoplasm.

References

[1] R.L. Barnhill, Textbook of Dermatophatology, McGraw-Hill Companies, USA, 1998.

[2] Y. Oda and T. Masazumi, Gen. Diagn. Pathol. 141 (1995) 121.

[3] This research was supported by the $\mathrm{CNPq}$ - Conselho Nacional de Pesquisa e Desenvolvimento. 

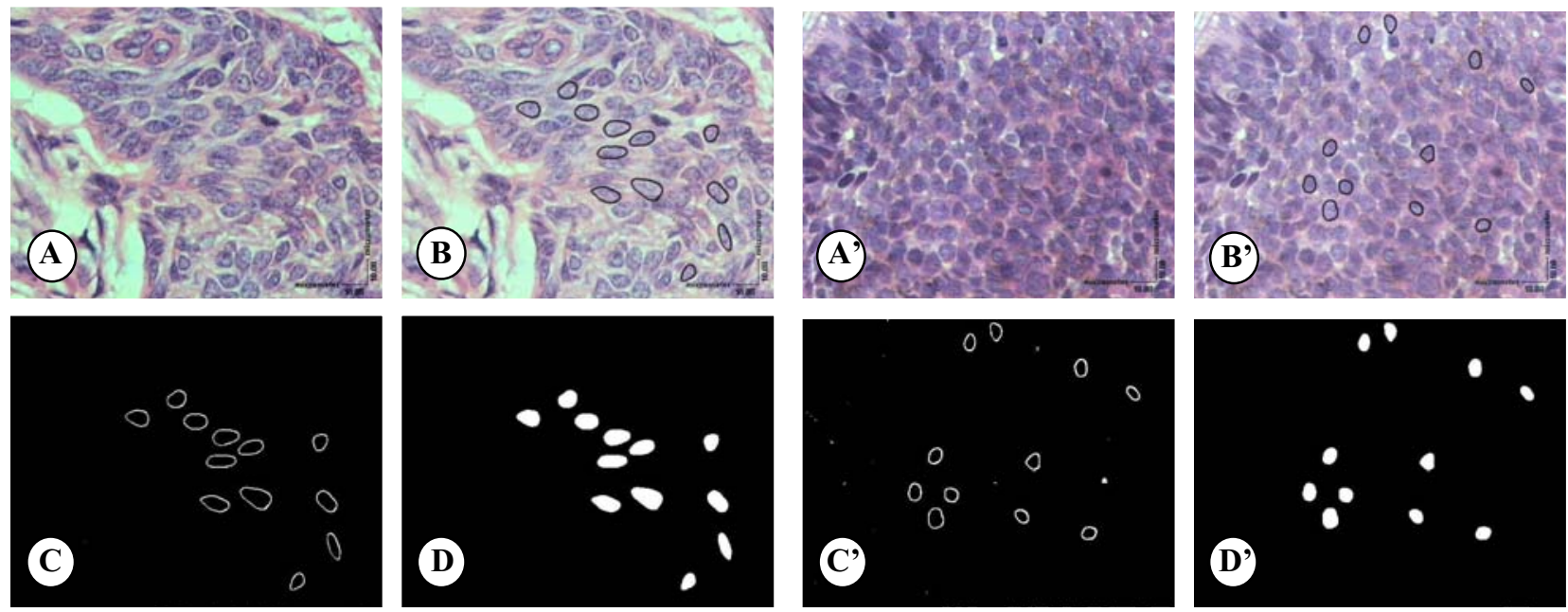

FIGURE 1. Sequence of images of the central area of a sclerodermiform basal cell carcinoma (left) and of a superficial basal cell carcinoma (right) during the execution of the macro for analysis of the preset nuclear parameters in the KS300 version 2.0 Kontron system. A \& A' - original image, HE; B \& B' - image with the nuclei delineated manually; C \& C' - semiautomatic binary image; D \& D' - binary image with retreat of black pixels inside of the nuclei and of white pixels out of the nuclei that corresponds to the final image submitted to the automatic measurement.

\begin{tabular}{|c|c|c|c|c|c|c|c|c|c|c|c|c|c|}
\hline \multicolumn{7}{|c|}{$\begin{array}{l}\text { Table 1. Database showing the lecture of central nuclei } \\
\text { in the field } 1 D \text { above. }\end{array}$} & \multicolumn{7}{|c|}{$\begin{array}{l}\text { Table 2. Database showing the lecture of central nuclei } \\
\text { in the field 1D' above. }\end{array}$} \\
\hline No & $\begin{array}{l}\text { AREA } \\
\mu \mathrm{m}^{2}\end{array}$ & $\begin{array}{c}\text { PERIMETER } \\
\mu \mathrm{m}\end{array}$ & $\begin{array}{l}\text { MIND } \\
\mu \mathrm{m}\end{array}$ & $\begin{array}{l}\text { MAXD } \\
\mu \mathrm{m}\end{array}$ & $\mathrm{EF}$ & $\mathrm{RF}$ & No & $\begin{array}{l}\text { AREA } \\
\mu \mathrm{m}^{2}\end{array}$ & $\begin{array}{c}\text { PERIMETER } \\
\mu \mathrm{m}\end{array}$ & $\begin{array}{c}\text { MIND } \\
\mu \mathrm{m}\end{array}$ & $\begin{array}{c}\text { MAXD } \\
\mu \mathrm{m}\end{array}$ & $\mathrm{EF}$ & $\mathrm{RF}$ \\
\hline 1 & 40.69 & 24.27 & 6.70 & 8.32 & 0.80 & 0.93 & 1 & 28.26 & 21.08 & 5.07 & 7.87 & 0.64 & 0.90 \\
\hline 2 & 45.57 & 26.77 & 6.55 & 9.66 & 0.68 & 0.92 & 2 & 26.47 & 20.04 & 4.88 & 7.27 & 0.67 & 0.95 \\
\hline 3 & 48.13 & 26.50 & 6.10 & 9.71 & 0.63 & 1.03 & 3 & 31.71 & 21.71 & 5.37 & 7.57 & 0.71 & 0.99 \\
\hline 4 & 52.17 & 28.86 & 6.34 & 10.91 & 0.58 & 0.96 & 4 & 22.66 & 19.13 & 4.39 & 7.09 & 0.62 & 0.93 \\
\hline 5 & 31.41 & 21.65 & 6.09 & 7.46 & 0.82 & 0.88 & 5 & 30.87 & 21.08 & 5.70 & 7.44 & 0.77 & 0.93 \\
\hline 6 & 45.98 & 27.34 & 5.74 & 10.69 & 0.54 & 0.95 & 6 & 30.22 & 21.14 & 5.85 & 7.27 & 0.81 & 0.9 \\
\hline 7 & 49.97 & 29.80 & 4.88 & 12.10 & 0.40 & 1.08 & 7 & 32.48 & 22.06 & 5.61 & 7.65 & 0.73 & 0.96 \\
\hline 8 & 75.55 & 35.50 & 7.80 & 13.36 & 0.58 & 0.92 & 8 & 28.26 & 20.19 & 5.85 & 6.78 & 0.86 & 0.91 \\
\hline 9 & 52.41 & 30.16 & 6.05 & 12.12 & 0.50 & 0.91 & 9 & 25.34 & 19.07 & 5.17 & 6.78 & 0.76 & 0.92 \\
\hline 10 & 47.89 & 27.29 & 6.04 & 9.90 & 0.61 & 1.02 & 10 & 43.84 & 25.12 & 6.34 & 8.71 & 0.73 & 1.01 \\
\hline 11 & 36.82 & 27.05 & 4.56 & 11.18 & 0.41 & 0.92 & 11 & 27.31 & 20.04 & 5.53 & 6.83 & 0.81 & 0.92 \\
\hline 12 & 27.78 & 20.94 & 5.17 & 7.81 & 0.66 & 0.88 & & & & & & & \\
\hline
\end{tabular}

Table 3. Mean value and standard deviation of the nuclear parameters of the central area of basaloid cell cutaneous neoplasms.

\begin{tabular}{|c|c|c|c|c|c|c|c|c|c|c|}
\hline \multirow{2}{*}{$\begin{array}{c}\text { Nuclear } \\
\text { parameter }\end{array}$} & \multicolumn{2}{|c|}{ Scl BCC } & \multicolumn{2}{|c|}{ Nod BCC } & \multicolumn{2}{|c|}{ Sup BCC } & \multicolumn{2}{|c|}{ TB } & \multicolumn{2}{|c|}{ TE } \\
\hline & Mean & SD & Mean & SD & Mean & $\mathrm{SD}$ & Mean & SD & Mean & SD \\
\hline $\operatorname{area}\left(\mu \mathrm{m}^{2}\right)$ & 41.03 & 14.15 & 43.26 & 12.71 & 33.82 & 10.67 & 34.63 & 10.43 & 27.15 & 8.81 \\
\hline perimeter $(\mu \mathrm{m})$ & 25.91 & 4.94 & 25.94 & 4.15 & 22.99 & 3.89 & 23.02 & 3.63 & 20.47 & 4.05 \\
\hline $\mathrm{m}$ diameter $(\mu \mathrm{m})$ & 5.70 & 1.15 & 6.15 & 0.98 & 5.33 & 0.93 & 5.55 & 0.94 & 4.87 & 0.86 \\
\hline $\mathrm{Im}$ diameter $(\mu \mathrm{m})$ & 9.72 & 2.20 & 9.46 & 1.77 & 8.51 & 1.70 & 8.36 & 1.52 & 7.53 & 1.79 \\
\hline factor & 0.61 & 0.14 & 0.67 & 0.12 & 0.64 & 0.13 & 0.68 & 0.12 & 0.66 & 0.12 \\
\hline ity factor & 0.92 & 0.04 & 0.93 & 0.04 & 0.92 & 0.04 & 0.93 & 0.04 & 0.92 & 0.04 \\
\hline
\end{tabular}

Mean value \& yellow boxes $=\mathrm{p}<0.05$ of Scl BCC and Nod BCC vs. Sup BCC, TB, and TE; SD value \& yellow boxes $=\mathrm{p}<0.05$ of Scl BCC vs. Sup BCC, TB, and TE. Mann-Whitney U test. Other statistical differences are not shown. 